\title{
Synergistic effect of titanium dioxide (TiO2) and ionizing radiation on thermal and mechanical properties of carboxymethyl cellulose (CMC) for potential application in removal of basic dye from wastewater
}

Yasser Gad ( $\nabla$ yasser2uk@yahoo.com )

National Centre for Radiation Research and Technology https://orcid.org/0000-0002-6973-0701

Hussein E. Ali

National Center for Radiation Research and Technology

El-Sayed A. Hegazy

National Center for Radiation Research and Technology

Original Research Full Papers

Keywords: carboxymethyl cellulose, TiO2, composite films, y-radiation, Basic violet 7 dye

Posted Date: February 2nd, 2021

DOI: https://doi.org/10.21203/rs.3.rs-161064/v2

License: (1) (i) This work is licensed under a Creative Commons Attribution 4.0 International License.

Read Full License 


\title{
Synergistic effect of titanium dioxide $\left(\mathrm{TiO}_{2}\right)$ and ionizing radiation on thermal and mechanical properties of carboxymethyl cellulose (CMC) for potential application in removal of basic dye from wastewater
}

\author{
Yasser H. Gad ${ }^{1}$, Hussein E.Ali ${ }^{2}$ and El-Sayed A. Hegazy ${ }^{1}$ \\ ${ }^{1}$ Polymer Chemistry Department, National Center for Radiation Research and Technology, Atomic \\ Energy Authority P.O. Box 29, Nasr City, Cairo, Egypt \\ ${ }^{2}$ Radiation Chemistry Department, National Center for Radiation Research and Technology, Egyptian \\ Atomic Energy Authority P.O. Box 29, Nasr City, Cairo, Egypt.
}

\begin{abstract}
Carboxymethyl cellulose $(\mathrm{CMC}) /$ titanium dioxide $\left(\mathrm{TiO}_{2}\right)$ was prepared using gamma irradiation at different doses. Carboxymethyl cellulose was used as a matrix and $\mathrm{TiO}_{2}$ in different contents was added $(0.25,0.5,1,1.5 \mathrm{wt} \%)$ as a filler. The polymer composite film were irradiated at doses of $5, \quad 10$ and $15 \mathrm{kGy}$ using ${ }^{60} \mathrm{Co} \gamma$-ray to form crosslinked network structure. The prepared composite films were described by different diagnostic procedures including X-ray diffractometer, scanning electron microscope (SEM), FTIR as well as thermal and mechanical properties measurements. $\mathrm{CMC} / \mathrm{TiO}_{2}$ composite films was used for removal of basic Violet 7 dye. The adsorption of the dye match with the Langmuir model across chemical monolayer adsorption performance. Adsorption kinetic of dyes was set up to be regular to pseudo second order kinetic model. The results showed that the prepared composite films significantly removed this basic violet 7 dye with maximum absorption capacity ( $123.6 \mathrm{mg} / \mathrm{g})$.
\end{abstract}

Keywords: carboxymethyl cellulose, $\mathrm{TiO}_{2}$, composite films, $\gamma$-radiation. Basic violet 7 dye.

corresponding author: yasser2uk@yahoo.com, tel. 002-22746791 and fax.002-22749298.

\section{Introduction}

Water contamination happens in various ways, however an enormous quantity of water pollution, as a product of different industrial effluents, happens during the pollution with organic, inorganic and high volume of dyes and this causes the contamination of environment and the orderly health problems for living frameworks [Khan, \& Lo, 2015]. Nevertheless, the pollution of water by dangerous dyes has become a crucial problem, universal because of their persistent bioaccumulation, low degradability and their high harmfulness [Sahraei \& Ghaemy, 2017]. There are various methods, for example: biodegradation, catalytic degradation and oxidation, for the elimination of pollutants [Khanday et al. 2017]. Nevertheless, these procedures are more responsive and consistent, anyway additional time-consuming, costly, cumbersome, laborious and tedious. Henceforth, sensitive, a simple, direct analytical and economical process is the adsorbent technique. In the adsorbent technique, hydrophilic polymeric hydrogels can assume a fundamental role in the elimination of pollutant from the waste water [Sahraei \& Ghaemy, 2017]. Hydrogels have three-dimensional, tissue like network, crosslinked and insoluble [He et al.,2016, Wang \& Wang, 2016]. These characteristics are high sorption capacity, important for water safeguarding and the removal of pollutants. In the advancement of such system, polysaccharide polymers are supplementary attractive than the synthetic polymers, on account of their functional properties, for example; great hydrophilicity, biocompatibility and biodegradation[Sharma et al., 2015]. Carboxymethyl cellulose (CMC) has been broadly utilized for the preparation of new designed hydrogels $[7,8]$. This is for the reason that CMC is a biodegradable natural anionic polysaccharide and biocompatible that can be highly soluble in the water and thus, rising the viscosity of the water [9]. The consolidation of a 
limited quantity of inorganic particles can improve the exhibition of thermal, mechanical, electrical, optical, antimicrobial and catalytic properties of the polymer structure [10-12]. $\mathrm{TiO}_{2}$ is notable for its numerous favorable circumstances, Titanium dioxide $\left(\mathrm{TiO}_{2}\right)$ is generally utilized in a variety of medical, food and biological yield [13]. The incorporation of $\mathrm{TiO}_{2}$ particles into polymeric network is being considered extensively in light of their significant properties, for example, hydrophilic properties, good stability, UV blocking ability, excellent photocatalytic, high oxidation power, liberated from contamination, nontoxic , exhibit antimicrobial activity and chemically inert material [14].

Numerous crosslinkers are generally utilized for polymers crosslinking yet these crosslinkers are either poisonous or costlier and furthermore the crosslinking occur in the presence of organic solvents. Citric acid (CA) is a crosslinker has low toxicity and cost compared with the different crosslinkers. Along these lines, it has been utilized to improve the properties of cellulose in materials applications $[15,16]$. There are various techniques to improve the surface properties of polymeric materials or to incorporate new useful natural based polymer.

The critical character of plasticizers is to upgrade the processibility and flexibility of natural polymer such as starch and CMC by reducing the strong intermolecular interactions between polymer molecules [17]. consequently, increases the mobility of polymeric chains, which enhances the flexibility, ductility and extensibility of plasticized composite films. Actually, the addition of plasticizers decreases mechanical resistance of the polymer. In addition, plasticization is especially significant on biopolymer composite films, since the dehydration of these structures produces a highly cohesive composite with poor mechanical properties [18]. Since most plasticizers contain hydrophilic groups, these compounds can interface by methods for hydrogen bonds with polymer framework as well as with water particles, increasing the polymer water adsorption [19]. The majority familiar plasticizer utilized for starch based polymers are polyols such as glycerol and sorbitol. The enthusiasm for the utilization of glycerol is because of glycerol properties which lessens the intermolecular forces and increment the mobility of the polymer chains. It can likewise modify the mobility of water because of its ability to decrease the surface energy of aqueous solution [20].

Radiation polymerization has a lot of advantages over other conventional strategies' science it does not involve the utilization of the catalysts or added substances to start the reaction, no compelling reason to include any initiator or crosslinker, disinfection, no waste, more environment friendly and generally low running expense [21,22]. In this manner, in contrast to the chemical initiation technique, the radiation prompted technique leaves no chemical residues, is free of pollution, consequently the purity of the processed yield can be kept up. In the majority cases of polymerization initiated by high energy radiation, easy to control, the processes are homogeneous and the reactions are not temperature dependent [23, 24]. Additionally, ionizing radiation has been known as an advantageous tool for improving the polymeric materials through grafting, crosslinking and degradation strategies [25].

In this study, preparing of dyes adsorbent composite films based on $\mathrm{CMC}$ and $\mathrm{TiO}_{2}$, which are neither harmful nor costly polymer composite film were done utilizing a direct radiation method. The properties of unirradiated and irradiated composite films were evaluated by utilizing different analytical devices, for example, FTIR, XRD, TGA and SEM. The adsorption isotherm model and kinetic studies for adsorption of the basic violet 7 dye onto $\mathrm{CMC} / 1.5 \mathrm{TiO}_{2}-10 \mathrm{kGy}$ hydrogel composite film has been investigated. The results showed that the prepared composite films significantly removed this dye with maximum adsorption capacity $(123.6 \mathrm{mg} / \mathrm{g})$. 


\section{Experimental}

\subsection{Material}

- Basic Violet 7 dye (Astrazon Red 6B), molecular formula $\left(\mathrm{C}_{24} \mathrm{H}_{30} \mathrm{~N}_{2} \mathrm{Cl}_{2}\right)$, molecular weight (416), was supplied by Dystar (Cairo, Egypt).

- Carboxymethyl cellulose (CMC) (purchased from El Gomhoria company, Cairo, Egypt).

- Titanium dioxide $\left(\mathrm{TiO}_{2}\right)$ was produced from KARMA for food colors flavors \& Fragrances, code No. 77891, Cairo, Egypt.

- Citric acid E.P (monohydrate) $\mathrm{C}_{6} \mathrm{H}_{8} \mathrm{O}_{7} \cdot \mathrm{H}_{2} \mathrm{O}, \quad \mathrm{M} . \mathrm{W}=210.14$ Mfr. By ALPHA CHEMIKA,INDIA, was used as crosslinker to prevent CMC from dissolution.

- Glycerol 99.5 \% , (Mwt = 92.09) was provided from Gomhoria pharmaceutical company, Egypt. glycerol was used as plasticizer to make the composite film more flexible.

\subsection{Preparation of $\mathrm{CMC} / \mathrm{TiO}_{2}$ Composite films:}

CMC (3.0g ) was added to $100 \mathrm{ml}$ of deionized water with stirring for about $4 \mathrm{~h}$. until complete miscibility. The desired amount of glycerol (20\%) was added as a plasticizer. At that point $5 \%$ citric acid (CA) was added to the solution to reduce the solubility of the prepared composite films ( just as a crosslinking agent). During the stirring the required amount of $\mathrm{TiO}_{2}$ was included with various proportions $(0.25,0.5,1.0,1.5 \mathrm{wt} \%)$ to the solution. Then placed in sonicator for 30 minutes to get enormous homogeneity. The composite film was removed, the foam was skimmed off and the composite film was poured in leveled polystyrene petri dishes then irradiated at doses of 5, 10 and $15 \mathrm{kGy}$ using ${ }^{60} \mathrm{Co} \gamma$ ray to form crosslinked network structure and after that dried for $48 \mathrm{~h}$. at room temperature to form the composite films.

\subsection{Irradiation method:}

Irradiation was completed at a dose rate of $0.33 \mathrm{~Gy} / \mathrm{s}$ in air using ${ }^{60} \mathrm{Co}$ gamma cell facility situated at National Center for Radiation Research and Technology (NCRRT), Cairo, Egypt.

\subsection{Characterization}

\subsubsection{Mechanical testing:}

Mechanical properties such as elongation at break and tensile strength of the prepared $\mathrm{CMC} / \mathrm{TiO}_{2}$ composite films were carried out utilizing a Mecmesin equipment ( model 10-I, Britain) utilizing a crosshead speed of $5 \mathrm{~mm} \mathrm{~min}^{-1}$ and load $500 \mathrm{~N}$ as per ASTM D-638 standards.

\subsubsection{Morphology and tobograghy measurement:}

The fracture surfaces SEM micrographs were taken with a JSM-5400 electron microscope, JEOL, Japan. A sputter coater was utilized to pre-coat conductive gold onto the fracture surfaces before watching the micrograghs at $30 \mathrm{kv}$.

\subsubsection{Thermogravimetric analysis (TGA):}

The TGA thermograms were performed by a Shimadzu TGA instrument ( Kyoto, Japan)

\subsubsection{FTIR Spectroscopy:} USA.

The infrared spectra were performed utilizing the Thermo scientific Nicolet iS 10,

\subsubsection{X-Ray Diffraction (XRD):}

The XRD of plasticized $\mathrm{CMC} / \mathrm{TiO}_{2}$ composite film before and after irradiation were carried out by a completely automated x-ray diffractometer (Shimadzu type XD-DI). X-ray diffraction pattern was recorded in the range of $2 \theta$ on Philips $\mathrm{Pw} 1730$. The diffraction 
patterns were performed with nickel filter ( Cuka) $\lambda=1.45^{\circ} \mathrm{A}$. The $\mathrm{x}$-ray diffractogram was gotten utilizing the following conditions: filament current $=28 \mathrm{~mA}$, voltage $=40 \mathrm{kv}$, scanning speed $=20 \mathrm{~mm} / \mathrm{min}$.

\subsection{Application:}

- Uptake of basic violet 7 dye onto irradiated $\mathrm{CMC}^{\mathrm{T}} \mathrm{TiO}_{2}$ composite film:

Basic violet 7 dye is a cationic water soluble dye; it was chosen as a model dye to investigate its uptake using $\mathrm{CMC} / \mathrm{TiO}_{2}$ composite film. The dye stock concentration (500 $\mathrm{mg} / \mathrm{l})$ in proper extents to the required concentrations $(10-250 \mathrm{mg} / \mathrm{l})$ were set up by dilution of the stock solution. $100 \mathrm{mg}$ of polymeric composite film was included into $59 \mathrm{ml}$ of dye solutions of definite concentration in each test bottle. The bottles were shaken in a thermostatic mechanical shaker at $30{ }^{\circ} \mathrm{C}$ with a speed $(100 \mathrm{rpm})$ for time intervals extend (128 h.). The effect of the initial $\mathrm{pH}$ of dye solution on the adsorption onto the prepared composite films were studied, for a $\mathrm{pH}$ range $(2-11)$ at initial dye concentration $(100 \mathrm{mg} / \mathrm{l})$ and contact time 4 hours to determine the optimum $\mathrm{pH}$. After each experiment, the dye concentration was determined by measuring its absorption at $\lambda \max =544 \mathrm{~nm}$ by using UV/Vis double beam Unicam UV2 spectrophotometer. The removal (\%) efficiency and the amount of dye adsorbed (q) (mg/g) were determined by the following equations:

$$
\begin{aligned}
& \text { Removal }(\%) \text { efficiency }=\left(\frac{\left.C_{0}-C_{e}\right) V}{C_{0}} \times 100\right. \\
& \text { Amount adsorbed }\left(q_{e}\right)=\frac{\left(C_{0}-C_{e}\right) V}{m} \\
& \text { Amount adsorbed }\left(q_{t}\right)=\frac{\left(C_{0}-C_{t}\right) V}{m}
\end{aligned}
$$

Where $\mathrm{C}_{\mathrm{e}}(\mathrm{mg} / \mathrm{l}), \mathrm{C}_{\mathrm{o}}(\mathrm{mg} / \mathrm{l}), \mathrm{qe}_{\mathrm{e}}(\mathrm{mg} / \mathrm{g})$ and $\mathrm{q}_{\mathrm{t}}(\mathrm{mg} / \mathrm{g})$ are the equilibrium and initial concentrations (mg/l) and the amount adsorbed of the dye at equilibrium and at the time $(\mathrm{t})$, respectively; $\mathrm{m}(\mathrm{g})$ is the weight of polymer composite film and $\mathrm{V}(\mathrm{l})$ is the volume of the basic violet 7 dye solution.

\section{Results and discussion}

\subsection{Fourier transform infrared spectroscopy (FTIR).}

As a result of stretching vibration of $-\mathrm{OH}$ groups, pure $\mathrm{CMC}$ represented a broad absorption band at 3350-3415 $\mathrm{cm}^{-1}$. Also, stretching vibration band at $2912 \mathrm{~cm}^{-1}$ for $\mathrm{C}-\mathrm{H}$ bonds was belonged. Tow intense peaks become obvious at 1460 and $1605 \mathrm{~cm}^{-1}$ were appointed to symmetric and asymmetric stretching of carboxylate groups and absorption band at $1320 \mathrm{~cm}^{-1}$ associated with $-\mathrm{OH}$ bending frequency [26]. The bands at 1175, 1605 and 1023 $\mathrm{cm}^{-1}$ corresponded to $\mathrm{C}-\mathrm{O}$ stretching frequencies of (C-O-C), which are stereotypical of the polysaccharide backbone. As can be seen in figure 1, the FTIR spectra of the prepared composite films were equivalent to the pure CMC composite film with low difference in peaks intensity. This suggests that the added $\mathrm{TiO}_{2}$ particles have not actuated fundamental changes in the composite film structure [27]. The absorption band at $3415 \mathrm{~cm}^{-1}$ which was doled out to $-\mathrm{OH}$ group stretching vibration, moderately moved to $3375 \mathrm{~cm}^{-1}$ with adding $1 \%$ wt of $\mathrm{TiO}_{2}$. This may be due to formation of hydrogen bonding between CMC and surface hydroxyl groups upon $\mathrm{TiO}_{2}$ [28]. Likewise, after the addition of $\mathrm{TiO}_{2}$, absorption bands at 692,765 and $1062 \mathrm{~cm}^{-1}$ were shifted to 735,796 and $1092 \mathrm{~cm}^{-1}$, respectively. The bands at 1605 and 1572 were disappeared and a new bands at their interval were appeared on $1.5 \%$ $\mathrm{TiO}_{2}$ formed composite films and a new bands at $452-800 \mathrm{~cm}^{-1}$ appeared for CMC based composite film which is due to $\mathrm{TiO}_{2}$. In affirming this, the spectra of the nanocomposite film (Polycaprolactone/Starch/TiO 2 ) bands at 412,532 and $656 \mathrm{~cm}^{-1}$ were identified for $\mathrm{TiO}_{2}$ 
particles. Besides, the bands in the range $400-850 \mathrm{~cm}^{-1}$ have been associated with Ti-O-Ti inorganic particles $[29,30]$.

\subsection{Mechanical properties}

The tensile strength and elongation at break are the mechanical properties that studied in this segment and the effect of irradiation dose and the content of $\mathrm{TiO}_{2}$ as a filler on this properties were studied. The variation in tensile strength of unirradiated and irradiated CMC samples containing different $\mathrm{TiO}_{2}$ content are represented in figure 2. It is shown that the TS values of irradiated samples $\mathrm{CMC} / \mathrm{TiO}_{2}$ samples were higher than the unirradiated sample. Additionally, it was seen that the TS increases as irradiation dose increase up to $10 \mathrm{kGy}$ and it tends to decrease at higher doses above $10 \mathrm{kGy}$ at a given amount of $\mathrm{TiO}_{2}$. This increase in TS values is a result of radiation crosslinking in the prepared composite film up to $10 \mathrm{kGy}$, through at higher doses degradation occur. Meanwhile, the higher the content of $\mathrm{TiO}_{2}$ the higher the TS at a given irradiation dose. The reinforcement of $\mathrm{TiO}_{2}$ might be credited to the higher surface area of $\mathrm{TiO}_{2}$ that in contact with $\mathrm{CMC}$ causing a decent dispersion of $\mathrm{TiO}_{2}$ in the polymer network and strong interaction between $\mathrm{TiO}_{2}$ and $\mathrm{CMC}$. In this manner, high stress between $\mathrm{CMC}$ and $\mathrm{TiO}_{2}$ is relied upon to happen showing the reinforcing effect of $\mathrm{TiO}_{2}$ [31]. The TS values increases with introducing $\mathrm{TiO}_{2}$ in $\mathrm{CMC}$ is due to compatibility between $\mathrm{TiO}_{2}$ and $\mathrm{CMC}$ matrix of the composite film. From the data we found that an increase in the stress related to $\mathrm{TiO}_{2}$ content as a result of irradiation. This gives another factor for the improvement in TS. Also, due to irradiation with addition of $\mathrm{TiO}_{2}$ the function groups of intercalation agent may support extra additional sites for crosslinking. The Ts increase as a result of irradiation CMC of composite film may be due to the formation of free radicals that joined with each other to form crosslinked structure or with $\mathrm{TiO}_{2}$ through hydrogen bonding.

The change in the elongation at break of the prepared composite film samples relies on the nature polymer and the degree of crosslinking, which limits the movement of polymer chains against the applied force. Figure 3 represent the effect of irradiation dose and $\mathrm{TiO}_{2} \%$ on the elongation at break. It tends to be seen that an orderly decrease in $\mathrm{Eb}$ is observed due to the increase of $\mathrm{TiO}_{2}$ content, this is something contrary to TS. This may be due to reinforcement at low $\mathrm{TiO}_{2}$ content causes a decrease in the elongation. Additionally, clearly $\mathrm{Eb}$ decreases consistently for all $\mathrm{CMC} / \mathrm{TiO}_{2}$ composite film with increasing the irradiation dose. This is ascribed to the formation of crosslinking network structure in the polymer, Which limited the mobility of the molecular chains through drawing [31]. At higher doses degradation is predominant, which gives another factor contributes a lot in decreasing the values of elongation at break.

\subsection{X-ray diffraction investigation (XRD)}

$\mathrm{XRD}$ was done to perceive the change in the morphology of the composite film by means of checking the position and intensity of reflection as appeared in figure 4. XRD sample of $\mathrm{CMC} / \mathrm{TiO}_{2}$ showed an intense diffraction peak characteristic to $\mathrm{TiO}_{2}$ at $2 \theta=25.6$ ${ }^{\circ} \mathrm{A}$ (101). While the blank CMC showed a broad peak at $2 \theta=20.8^{\circ} \mathrm{A}$ indicating a semicrystalline structure and becomes more comprehensible with addition of $\mathrm{TiO}_{2}$. Also, the intensity of the $\mathrm{CMC}$ beak of the prepared composite film decreased due to interaction between $\mathrm{CMC}$ and $\mathrm{TiO}_{2}$ particles and the crystallinity of $\mathrm{TiO}_{2}$ particles does not change during the preparation process. Additionally, the decrease of the composite film crystallinity could be the indication of formation of hydrogen bonding between $\mathrm{CMC}$ and $\mathrm{TiO}_{2}$ [31-33]. Generally, $\gamma$-irradiation at $10 \mathrm{kGy}$ for $\mathrm{CMC} / 1.5 \% \mathrm{TiO}_{2}$ composite film caused a reduce in the 
crystallinity of the composite films, which may be due to formation of crosslinked composite film.

\subsection{Surface morphology (SEM)}

The surface micrographs of blank $\mathrm{CMC}$, unirradiated and irradiated $\mathrm{CMC} / \mathrm{TiO}_{2}$ composite films were produced in figure 5 at a magnification power of $1000 \mathrm{X}$. The figure indicates that the surface feature of blank CMC is smooth, soft, homogenous and coherent. Addition of $\mathrm{TiO}_{2}$ particles to unirradiated $\mathrm{CMC}$ led to roughness with aggregated white spots, indicating the convenient distribution of $\mathrm{TiO}_{2}$ particles into the hosting polymer network. Meanwhile, the irradiated $\mathrm{CMC} / \mathrm{TiO}_{2}$ composite films displayed better interfacial adhesion with the polymer matrix.

\subsection{Thermal stability}

Figures 6,7 showed the thermal stability of CMC, unirradiated and irradiated CMC/1.5\% $\mathrm{TiO}_{2}$ composite films. Which represented that the irradiated samples is thermally more stable than the corresponding polymer from which it was synthesized. The degradation of blank CMC starts at $225{ }^{\circ} \mathrm{C}$ with $20 \%$ degradation. In comparison, the degradation of unirradiated $\mathrm{CMC} / \mathrm{TiO}_{2}$ started at $230{ }^{\circ} \mathrm{C}$ with just $17 \%$ weight loss and the irradiated sample started at $234{ }^{\circ} \mathrm{C}$ with $15 \%$ loss, which making it more stable than the native material from which it was synthesized. From table (1) it can be seen that the unirradiated and irradiated $\mathrm{CMC} / \mathrm{TiO}_{2}$ composite films display higher $\mathrm{T}_{\max }$ than the neat $\mathrm{CMC}$ and $\mathrm{T}_{\max }$ increases with irradiation. Which pointed that the thermal stability of irradiated $\mathrm{CMC} / \mathrm{TiO}_{2}$ composite films is higher than that of the unirradiated ones. The thermograms concludes higher degradation temperature for the irradiated than the blank CMC and the unirradiated samples. That is might be confirming improvement in the thermal stability ascribed to the formation of crosslinked structure.

\subsection{Uptake of basic violet 7 dye on $\mathrm{CMC} \mathrm{TiO}_{2}$ composite film}

The uptake of the dyes from discharge wastewater is a significant issue for the environment. In this study we used the irradiated CMC-20\% glycerol, $\mathrm{CMC} / 1.5 \% \mathrm{TiO}_{2}$ and $\mathrm{CMC} / 1.5 \% \mathrm{TiO}_{2}-10 \mathrm{kGy}$ hydrogel composite films for the uptake of basic violet 7 dye from wastewater. Figure 7A represents the change in the absorbance of the dye solutions by blank $\mathrm{CMC}$, unirradiated and irradiated composite films after $24 \mathrm{~h}$., which decreases to approach zero, demonstrating the total removal of the dye by the irradiated $\mathrm{CMC} / \mathrm{TiO}_{2}$ composite film and confirmed by figure 7B that shows the effect of the adsorbent type: (A) blank CMC, (B) unirradiated $\mathrm{CMC} / \mathrm{TiO}_{2}$ and $(\mathrm{C})$ irradiated $\mathrm{CMC} / \mathrm{TiO}_{2}$ composite film.

\subsubsection{Effect of initial $\mathrm{pH}$ and initial concentration on the adsorption of the dye}

Figure 8 represents effect of initial $\mathrm{pH}$ on the adsorption of basic violet 7 dye onto $\mathrm{CMC} / \mathrm{TiO}_{2}$ composite film. In this study, $0.2 \mathrm{~g}$ of composite film was included into $50 \mathrm{ml}$ of dye solution of definite concentration $100 \mathrm{mg} / \mathrm{l}$ in each experimental bottle. The data represented that as the $\mathrm{pH}$ increases the dye uptake increases until reaches a maximum value at $\mathrm{pH}=8$, and afterward remained practically consistent over the range ( $9-11.0)$. At lower $\mathrm{pH}$ values in acidic medium, there will be a competition between the positively charged dye and $\mathrm{H}^{+}$of the aqueous medium toward the carboxylic groups of $\mathrm{CMC}$. As the $\mathrm{pH}$ increased ( neutral and basic medium ), a net negative charge formed on the surface of CMC due the dissociation of carboxylic groups onto $\mathrm{CMC}$, which enhance the attraction between the composite film and the dye. The chosen optimum $\mathrm{pH}$ for the adsorption process was $\mathrm{pH}=8$ as shown in figure 8 . Also, Figure 8 represents the effect of initial concentration of the basic violet 7 dye $(25-250 \mathrm{mg} / \mathrm{l})$ on the adsorption capacity $(\mathrm{mg} / \mathrm{g})$ of the dye onto the irradiated $\mathrm{CMC} / 1.5 \% \quad \mathrm{TiO}_{2}$ composite film. The results represented that the adsorption capacity increases as the initial dye concentration increases. Actually, the adsorption capacity of 
$\mathrm{CMC} / \mathrm{TiO}_{2}$ toward the basic violet 7 dye is strongly affected by the initial dye concentration. The higher the initial concentration of the basic dye, the stronger the driving forces of the concentration gradient and afterward the higher the adsorption capacity. The adsorption capacity of composite film for the basic violet 7 dye was found to be about $123.8 . \mathrm{mg} / \mathrm{g}$ at $\mathrm{pH}$ $=8$, initial concentration of dye $=100 \mathrm{mg} / \mathrm{l}$ and temperature $=30^{\circ} \mathrm{C}$ after $420 \mathrm{~min}$.

\subsubsection{Effect of contact time and temperature on the dye uptake}

Figures (9) represent the effect of contact time between the dye solution (initial conc. $100 \mathrm{mg} / \mathrm{l}$ ) and the prepared $\mathrm{CMC} \mathrm{TiO}_{2}$ polymer composite film at $\mathrm{pH}=8$ at different temperatures, which indicates that the adsorption process could be considered as quick process since the amount adsorbed reached $123.6 \mathrm{mg} / \mathrm{g}$ ) after $420 \mathrm{~min}$. From the figure we observed the adsorption increased with time till reaches equilibrium after $420 \mathrm{~min}$. this may be due to rapid attachment between the dye and the composite film at the first stage. Then after that, the attachment becomes slow because many of the available external sites of the polymeric composite film were occupied and, slow diffusion of the dye molecules into the pore spaces of the irradiated $\mathrm{CMC} / \mathrm{TiO}_{2}$ composite film. Temperature is an important factor on the adsorption process as shown in figure 9. Where amount adsorbed $(\mathrm{mg} / \mathrm{g})$ of the dye onto the irradiated $\mathrm{CMC} / 1.5 \% \mathrm{TiO}_{2}$ were studied at 298,308 and $318{ }^{\circ} \mathrm{K}$ at $\mathrm{pH}=8$ and adsorbent dosage $=0.2 \mathrm{~g}$. The adsorption capacity $(\mathrm{mg} / \mathrm{g})$ increased when the temperature increased from 298 to $308{ }^{\circ} \mathrm{K}$, which represented that the adsorption process is an endothermic process. When the temperature reached $318{ }^{\circ} \mathrm{K}$ a small change in the adsorption process occurred. This may be due to the thermal motion of the dye molecules increased and could run away the interaction and this process reaches balance.

3.6.3. Adsorption isotherm

The adsorption isotherms of basic violet 7 dye for the irradiated $\mathrm{CMC} / 1.5 \mathrm{TiO}_{2}$ at different temperatures are represented in figure 10. The data are fitted with the generally used Langmuir and Freundlich models, and the fitted parameters are exposed in Table 2. The Langmuir model is expressed in equation 4. What is more, the Freundlich isotherm describes the reversible adsorption and is not confined to the development of the monolayer is expressed in eq. (5).

$$
\begin{gathered}
\frac{C_{e}}{q_{e}}=\frac{1}{q_{m} K_{L}}+\frac{C_{e}}{q_{m}} \\
\ln q_{e}=\ln K_{f}+\frac{1}{n} \ln C_{e}
\end{gathered}
$$

where $\mathrm{K}_{\mathrm{L}}$ and $\mathrm{K}_{\mathrm{F}}$ are the binding constants in the Langmuir and Freundlich models, respectively and $1 / \mathrm{n}$ is empirical parameter in the Freundlich model.

The Langmuir model correlation coefficients $\left(\mathrm{R}^{2}\right)$ for the basic violet 7 dye adsorbed onto the irradiated $\mathrm{CMC} / 1.5 \% \mathrm{TiO}_{2}$ at different temperatures 298,308 and $318{ }^{\circ} \mathrm{K}$ were $0.9962,0.9969$ and 0.9972 , respectively. These values are higher than those acquire from the Freundlich model, for example, 0.7173, 0.6268 and 0.6878 , respectively. Furthermore, the obtained empirical parameters $(1 / \mathrm{n})$ from the Freundlich model for the adsorption of the basic violet 7 dye are all under 1.0, which are in general not compatible with the experimentally calculated adsorption values, while the $\mathrm{q}_{\mathrm{m}}$ values resulted from the Langmuir model are fitted with the experimental data in Table 2. This proposes that the adsorption of the dye follows the Langmuir model as opposed to the Freundlich model, representing a monolayer adsorption behavior of the investigated dye onto the irradiated $\mathrm{CMC} / 1.5 \% \mathrm{TiO}_{2}$.

\subsubsection{Adsorption kinetics}


The kinetics of basic violet 7 dye adsorption are determined to understand the adsorption behaviors for the irradiated $\mathrm{CMC} / 1.5 \mathrm{TiO}_{2}$ at different temperatures represented in figure 11. As regards, the irradiated $\mathrm{CMC} / 1.5 \mathrm{TiO}_{2}$, the data reveal that, at various temperatures, during the first $420 \mathrm{~min}$, the adsorption plateau showed up the adsorption amounts of 123.6, 138.6 and $142.7 \mathrm{mg} / \mathrm{g}$, respectively. While after $420 \mathrm{~min}$, the adsorbed amounts of the dye didn't change significantly $(126.1,138.7$, and $143.2 \mathrm{mg} / \mathrm{g}$, respectively). The kinetic adsorption of the basic violet dye for the irradiated $\mathrm{CMC} / 1.5 \mathrm{TiO}_{2}$ was linearly evaluated utilizing the pseudo-first-order (eq. 6) and pseudo-second-order kinetic (eq. 7) and the fixed data were shown in figure 11.

$$
\begin{array}{cc}
\log \left(q_{e}-q_{t}\right)= & \log q_{e}-k_{1} t / 2.303 \\
t / q_{t}= & 1 / k_{2} q_{e}{ }^{2}+t / q_{e}
\end{array}
$$

where $\mathrm{K}_{1}\left(\mathbf{m i n}^{-1}\right)$ and $\mathrm{K}_{2}\left(\mathbf{m i n}^{-1}\right)$ are the pseudo-first-order and pseudo-second-order rate constants.

The kinetic parameters fitted from the experimental data were summarized in Table 2. The linear correlation coefficients $\left(\mathrm{R}^{2}\right)$ resulted from the pseudo-second-order kinetics for the adsorption of the basic violet 7 dye at various temperatures 298,308 and $318{ }^{\circ} \mathrm{K}$ are close to 1.0 (0.9911 or 0.9971 and 0.9909 , respectively). These values are higher than those acquired from the pseudo-first-order, for example, 0.5049, 0.9141 and 0.9256, respectively. Moreover, the determined equilibrium adsorption values ( $\left.\mathrm{q}_{\mathrm{e}, \mathrm{cal}}\right)$ obtained from the pseudo-second-order kinetic model for irradiated $\mathrm{CMC} / 1.5 \mathrm{TiO}_{2}$ composite film towards the dye are 129.8, 179.8, and $148.9 \mathrm{mg} / \mathrm{g}$, respectively . Where, $\left(\mathrm{q}_{\mathrm{e}, \mathrm{cal}}\right)$ obtained from the pseudo-first-order kinetic model in general not compatible with the experimentally calculated adsorption values. For that reason, the fitted and the experimental values illustrate considerable consistence here when the pseudo-second-order kinetic model was used.

It is significant that the prepared $\mathrm{Fe}_{3} \mathrm{O}_{4} / \mathrm{SiO}_{2} / \mathrm{GMA} / \mathrm{AN}$ (amidoxime) nanocomposite film in this work have superior adsorptivity for the basic red dye than that for other CMC polymeric nanocomposite film as Adsorbents., as listed in Table 3.

\section{Conclusion}

$\mathrm{CMC} / \mathrm{TiO}_{2}$ composite film with various content of $\mathrm{TiO}_{2}$ were prepared using gamma irradiation source which and characterized by FTIR, TGA and SEM. Additionally, Also, the mechanical behavior of the developed composite films was investigated and the dose yielded best values was adopted to use for the application of interest. The possibility of using the 10 $\mathrm{kGy}$ irradiated $\mathrm{CMC} / 1.5 \% \mathrm{TiO}_{2}$ in the removal of basic violet dye from wastewater was examined under the following conditions: optimum irradiation dose $10 \mathrm{kGy}$, adsorbent $\mathrm{CMC} / \mathrm{TiO}_{2}$ amount: $0.2 \mathrm{~g}$, contact time: $420 \mathrm{~min}$., initial dye concentration: $100 \mathrm{mg} / \mathrm{l}$ and $\mathrm{pH}$ 8. In this investigation, $\mathrm{CMC} / 1.5 \% \mathrm{TiO}_{2}$ demonstrated excellent adsorption capacity ( 123.6 $\mathrm{mg} / \mathrm{g}$ ) for uptake of basic violet 7 dye from its solution. The adsorption of the dye follows the Langmuir model a with chemical monolayer adsorption behavior. Adsorption kinetic of dyes was set up to be regular to pseudo second order kinetic model. Hence, the $\mathrm{CMC}_{\mathrm{TiO}}$ composite film can be potentially used for the uptake of dye in addition to industrial applications.

\section{References}

1. Khan, M., \& Lo, I. M. C. (2015). Removal of ionizable aromatic pollutants from contaminated water using nano $\gamma-\mathrm{Fe}_{2} \mathrm{O}_{3}$ based magnetic cationic hydrogel: Sorptive performance, magnetic separation and reusability. Journal of Hazardous Materials, 322, 195-204. http://dx.doi.org/10.1016/j.jhazmat.2016.01.051 
2. Sahraei, R., \& Ghaemy, M. (2017). Synthesis of modified gum tragacanth/grapheneoxide composite film hydrogel for heavy metal ions removal and preparation of silver nanocomposite film for antibacterial activity. Carbohydrate Polymer, 157,823-833. http://dx.doi.org/10.1016/j.carbpol.2016.10.059.

3. Khanday, W. A., Asif, M., \& Hameed, B. H. (2017). Cross-linked beads of activated oil palm ash zeolite/chitosan composite film as a bio-adsorbent for the removal of methylene blue and acid blue 29 dyes. International Journal of Biological Macromolecules, 95, 895902. http://dx.doi.org/10.1016/j.ijbiomac.2016.10.075

4. He, S., Zhang, F., Cheng, S., \& Wang, W. (2016). Synthesis of sodium acrylate and acrylamide Copolymer/GO hydrogels and their effective adsorption for $\mathrm{Pb}^{2+}$ and $\mathrm{Cd}^{2+}$. ACS Sustainable Chemistry and Engineering, 4(7), 3948-3959. http://dx.doi.org/10.1021/acssuschemeng.6b00796.

5. Wang, L. Y., \& Wang, M. J. (2016). Removal of heavy metal ions by poly(vinylalcohol) and carboxymethyl cellulose composite film hydrogels prepared by a Freeze-Thaw method. ACS Sustainable Chemistry and Engineering, 4(5),2830-2837. http://dx.doi.org/10.1021/acssuschemeng.6b00336.

6. Sharma, R., Kaith, B. S., Kalia, S., Pathania, D., Kumar, A., Sharma, N., \& Schauer, C.(2015). Biodegradable and conducting hydrogels based on Guar gum polysaccharide for antibacterial and dye removal applications. Journal of Environmental Management, 162, 37-45. http://dx.doi.org/10.1016/j.jenvman.2015.07.044.

7. Kono, H., Ogasawara, K., Kusumoto, R., Oshima, K., Hashimoto, H., \& Shimizu, Y.(2016). Cationic cellulose hydrogels cross-linked by poly(ethylene glycol):Preparation, molecular dynamics, and adsorption of anionic dyes. Carbohydrate Polymers, 152, 170180. http://dx.doi.org/10.1016/j.carbpol.2016.07.011.

8. Wang, Z., Ning, A., Xie, P., Gao, G., Xie, L., Li, X., \& Song, A. (2017). Synthesis and swelling behaviors of carboxymethyl cellulose-based superabsorbent resin hybridized with graphene oxide. Carbohydrate Polymers, 157, 48-56. http://dx.doi.org/10.1016/j.carbpol.2016.09.070.

9. Raafat, A. I., Eid, M., \& El-Arnaouty, M. B. (2012). Radiation synthesis of superabsorbent CMC based hydrogels for agriculture applications. Nuclear Instruments and Methods in Physics Research, Section B: Beam Interactions with Materials and Atoms, 283, 71-76. http://dx.doi.org/10.1016/j.nimb.2012.04.011.

10. Jordan, J., Jacob, K. I., Tannenbaum, R., Sharaf, M. A. and Jasiuk, I.(2005). Materials Science and Engineering: A, 393 (1-2), 1-11.

11. Viswanathan, V., Laha, T., Balani, K., Agarwal, A. and Seal, S. , Materials Science and Engineering R 54 (2006) 121-285.

12. Damodar, R. A., You, S. J. and Chou, H. H., (2009) J. Hazard Mater,172(2-3), 13211328.

13. Kaewklin, P., Siripatrawan, U., Suwanagul, A., Lee, Y.S., 2018. Active packaging from chitosan-titanium dioxide nanocomposite film for prolonging storage life of tomato fruit. Int. J. Biol. Macromol. 112, 523-529. 
14. He, Q., Zhang, Y., Cai, X., Wang, S., 2016. Fabrication of gelatin- $\mathrm{TiO}_{2}$ nanocomposite film and its structural, antibacterial and physical properties. Int. J. Biol. Macromol. 84, 153-160.

15. Gawish, S. M. Abo El-Ola, A. M. Ramadan AAAE-KN (2012)," Citric acid used as a crosslinking agent for the grafting of chitosan onto woolen fabric" Journal of Applied Polymer Science, 123, 3345-3353.

16. Reddy N, Yang Y. "Citric acid crosslinking of starch films", Food Chem. 2010;118(3):702-11.

17. Aguirre, A.; Borneo, R.; León, A.E. "Properties of triticale protein films and their relation to plasticizing-antiplasticizing effects of glycerol and sorbitol". Ind. Crops Prod. 2013, 50, 297-303.

18. Melissa Gurgel Adeodato Vieira, Mariana Altenhofenda Silva and Marisa MasumiBeppu, "Natural-based plasticizers and biopolymer films: A review", (2011). European Polymer Journal. 47(3): p. 254-263.

19. Sandra Rivero, L Damonte, María Alejandra García, A Pinotti, "An insight into the role of glycerol in chitosan films", (2016). Food Biophysics. 11(2): p. 117-127.

20. Lavorgna, M., Piscitelli, F., Mangiacapra, P., and Buonocore, G. G., (2010). Study of the combined effect of both clay and glycerol plasticizer on the properties of chitosan films. Carbohydrate Polymers, 82: 291-298.

21. Tabata Y., Ito S. and Tagawa S., "CRC Handbook of Radiation Chemistry, CRC, Baston", (1991) p. 742.

22. Abd El-Mohdy H.L., Hegazy E.A., El-Nesr E.M., and El-Wahab M.A.," Synthesis, characterization and properties of radiation-induced Starch/(EG-co-MAA) hydrogels“, Arab J. Chem., 9, S1627 (2016).

23. Barsbay, M., Kodama, Y., Güven, O., 2014. Functionalization of cellulose with epoxy groups via initiated RAFT-mediated grafting of glycidyl methacrylate. Cellulose 21,40674079 .

24. Rymuszka, D., Terpiłowski, K., Sternik, D., Tomczynska-Mleko, M., Goncharuk, O., 2017. Wettability and thermal analysis of hydrophobic poly(methyl methacrylate)/silica nanocomposite films. Adsorpt. Sci. Technol. 35 (5-6), 560-571.

25. El-Arnaouty M.B., Abdel Ghaffar A. M. , Abdel Baky A. A. and Shama S. A., “ Radiation synthesis of hydrogels based on carboxymethyl cellulose and its application in removal of pollutants from wastewater", J. Vinyl\& Additive, (2017), 25, S1, E35-E43.

26. Damodar, R. A., You, S. J. and Chou, H. H.," Study the self cleaning, antibacterial and photocatalytic properties of TiO2 entrapped PVDF membranes.“, (2009) J. Hazard Mater,172(2-3), 1321-1328.

27. A.Abdel-Galil' H.E.Ali' A.Atta and M.R.Balboul "Influence of nanostructured $\mathrm{TiO}_{2}$ additives on some physical characteristics of carboxymethyl cellulose (CMC)" Journal of Radiation Research and Applied Sciences, 7, (1), 2014, 36-43.

28. Jinbao Zhang, Nick Vlachopoulos, Yan Hao, Thomas W. Holcombe, Gerrit Boschloo, Erik M. J. Johansson, Michael Grätzel, and Anders Hagfeldt," Efficient Blue-Colored Solid-State Dye-Sensitized Solar Cells: Enhanced Charge Collection by Using an in Situ 
Photoelectrochemically Generated Conducting Polymer Hole Conductor", ChemPhysChem 2016, 17, 1441 - 1445.

29. Jordan, J., Jacob, K. I., Tannenbaum, R., Sharaf, M. A. and Jasiuk, I.” Experimental trends in polymer nanocomposite films - A review“, (2005). Materials Science and Engineering: A, 393 (1-2), 1-11.

30. Lei, Y., Zhang, L. D. and Fan, J. C. "Fabrication, characterization and Raman study of $\mathrm{TiO}_{2}$ nanowire arrays prepared by anodic oxidative hydrolysis of $\mathrm{TiCl}_{3}$ “, (2001). Chemical Physics Letters, 338(4-6), 231-236.

31. Oleyaei, S. A., Zahedi, Y., Ghanbarzadeh, B. and Moayedi, A. A.," Modification of physicochemical and thermal properties of starch films by incorporation of $\mathrm{TiO}_{2}$ nanoparticles“, (2016). International Journal of Biological Macromolecules, 89, 256-264.

32. Ren, J., Wang, S., Gao, C., Chen, X., Li, W. and Peng, F. , "TiO2-containing PVA/xylan composite films with enhanced mechanical properties, high hydrophobicity and UV shielding performance“, (2015). Cellulose, 22(1), 593-602.

33. Sreekumar, P., Al-Harthi, M. A. and De, S.," Reinforcement of starch/polyvinyl alcohol blend using nano-titanium dioxide“", (2012). Journal of Composite film Materials, 46(25), 3181-3187.

34. Tayeb Benhalima , Hafida Ferfera-Harrar, Djahida Lerari," Optimization of carboxymethyl cellulose hydrogels beads generated by an anionic surfactant micelle templating for cationic dye uptake: Swelling, sorption and reusability studies", International Journal of Biological Macromolecules, 105(1), (2017), 1025-1042

35. Zirak, M., Abdollahiyan, A., Eftekhari-Sis, B. et al. "Carboxymethyl cellulose coated $\mathrm{Fe}_{3} \mathrm{O}_{4} @ \mathrm{SiO}_{2}$ core-shell magnetic nanoparticles for methylene blue removal: equilibrium, kinetic, and thermodynamic studies". Cellulose 25, 503-515 (2018).

36. C. Liu, A. Omer, X.-k. Ouyang, "Adsorptive removal of cationic methylene blue dye using carboxymethyl cellulose/k-carrageenan/activated montmorillonite composite film beads: isotherm and kinetic studies", Int. J. Biol. Macromol. 106 (2018) 823-833.

37. K. Kaur, R. Jindal, "Self-assembled GO incorporated CMC and chitosan-based nanocomposite films in the removal of cationic dyes", Carbohydr. Polym. 225 (2019), 115245

38. J. Liu, H. Chu, H. Wei, H. Zhu, G. Wang, J. Zhu, J. He, "Facile fabrication of carboxymethyl cellulose sodium/graphene oxide hydrogel microparticles for water purification”, RSC Adv. 6 (2016) 50061-50069. 
Figures

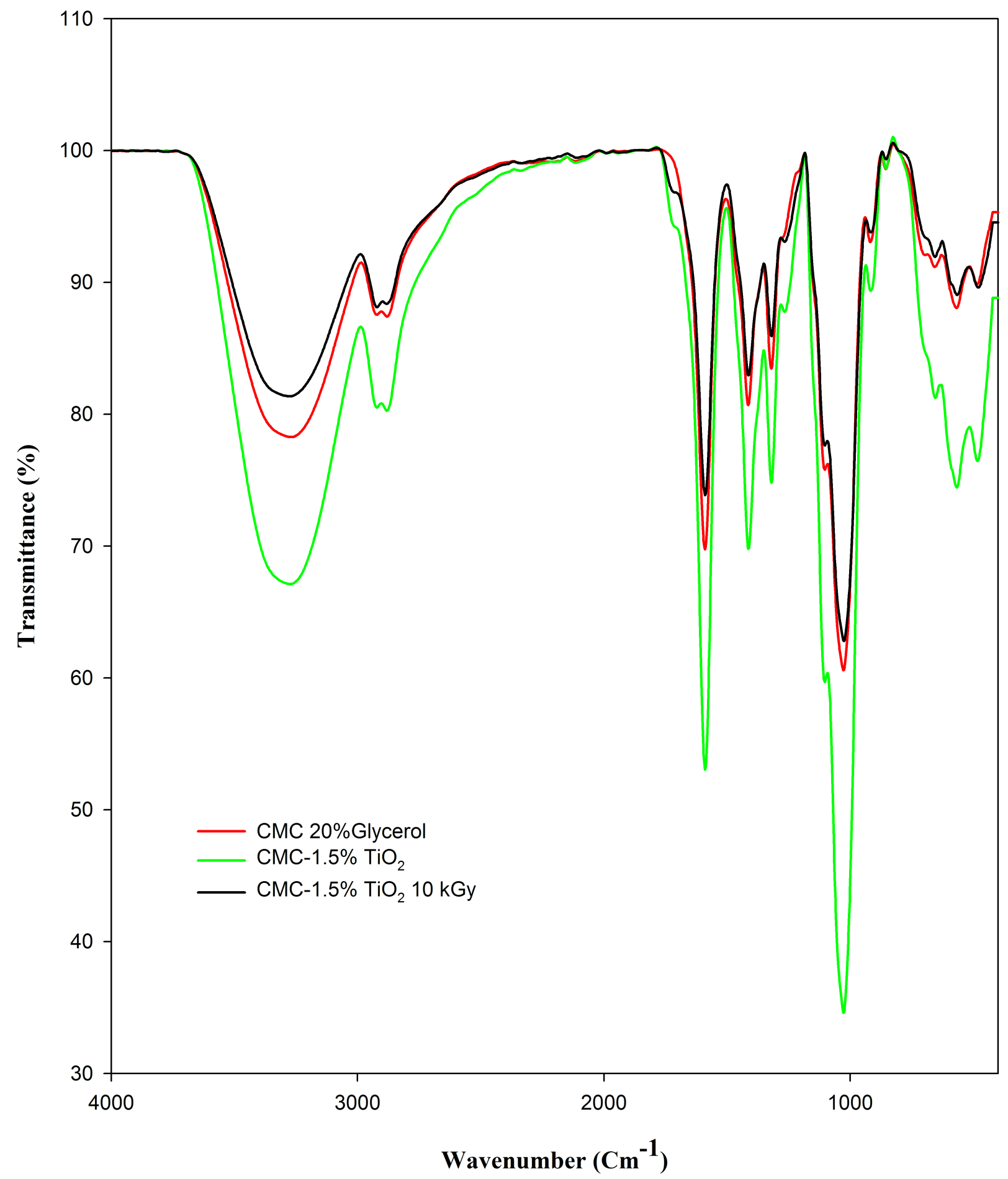

Figure 1

FTIR spectra of CMC-20\% Glycerol, CMC/1.5\% TiO2 and CMC/1.5\% TiO2 - 10kGy. 


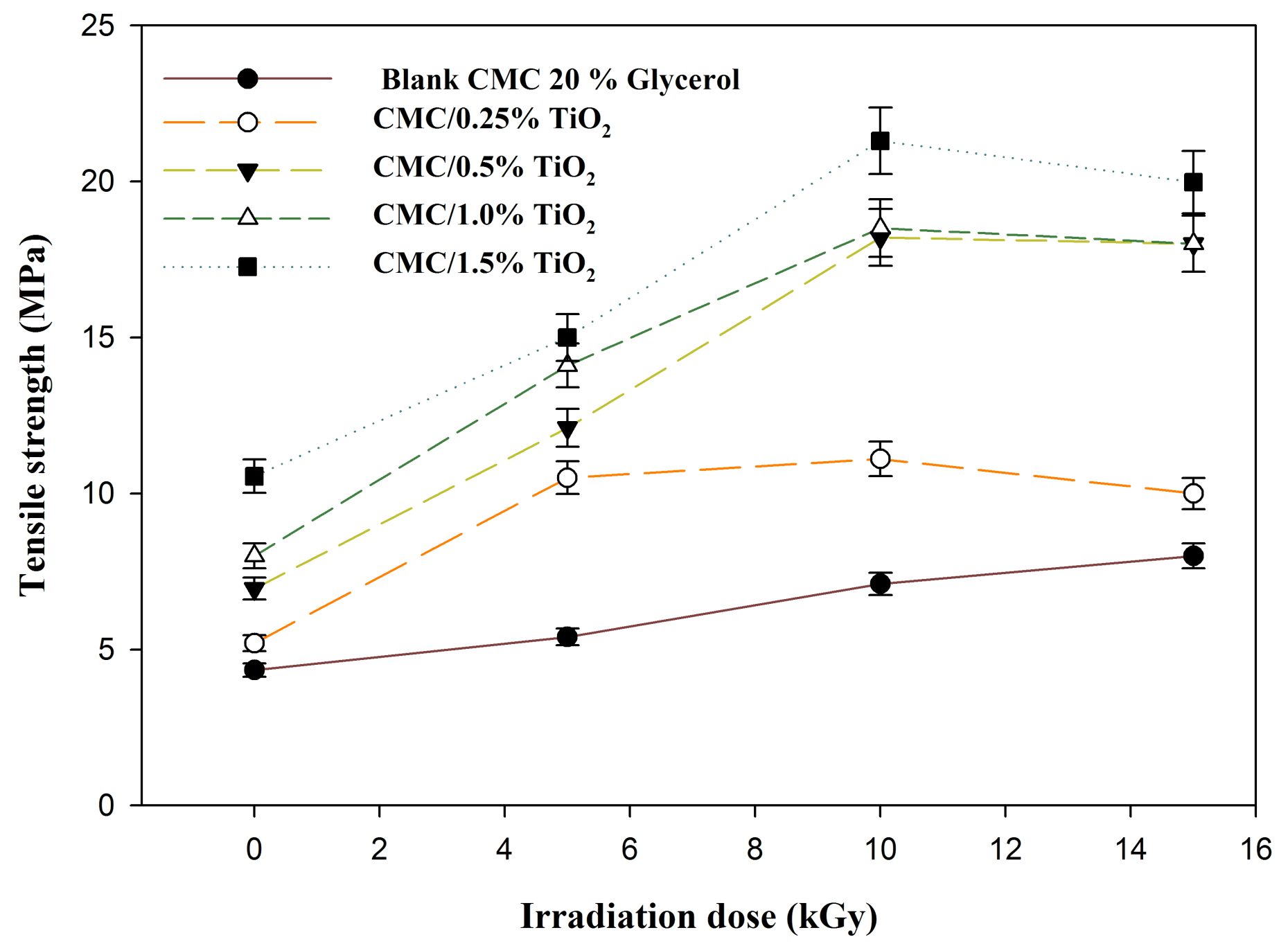

Figure 2

Effect of Irradiation dose (kGy) and TiO2 (\%) content on the Tensile strength (MPa) of carboxymethyl cellulose (CMC) films. 


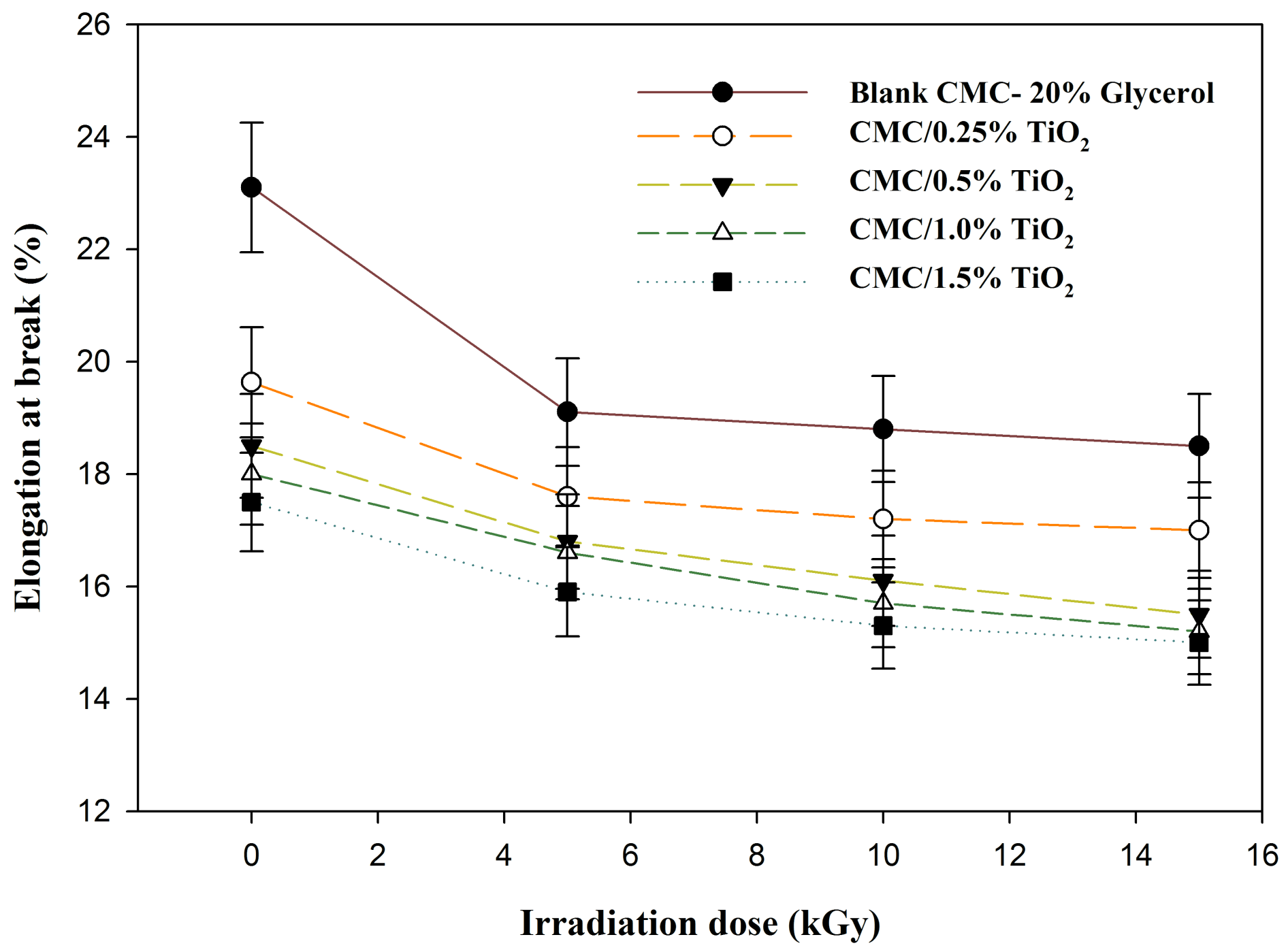

Figure 3

Effect of Irradiation dose (kGy) and TiO2 (\%) content on the Elongation at break (\%) of carboxymethyl cellulose (CMC) films. 


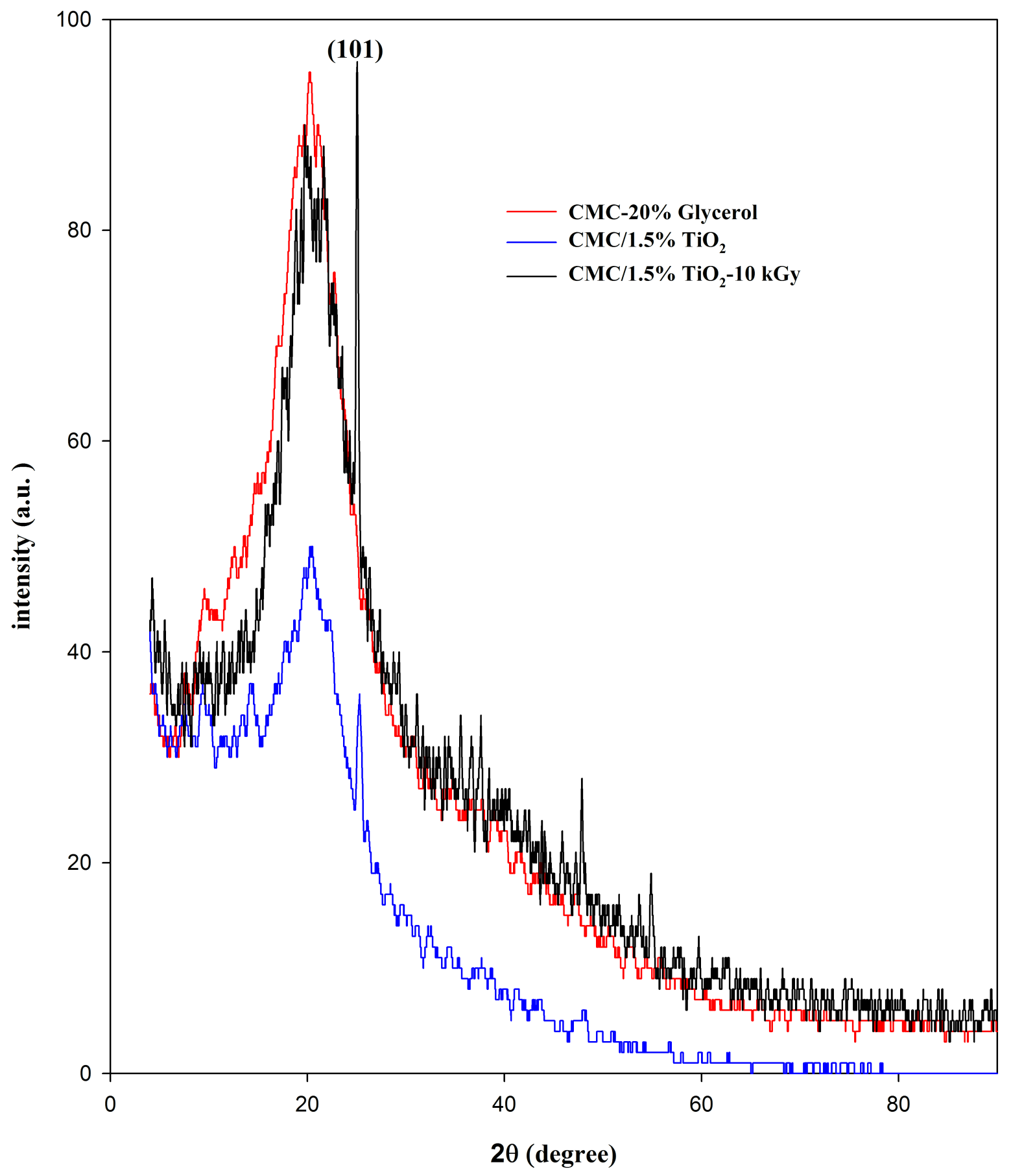

Figure 4

The X-ray diffraction patterns of CMC-20\% Glycerol, CMC/1.5\% TiO2and CMC/1.5\%TiO2-10kGy. 

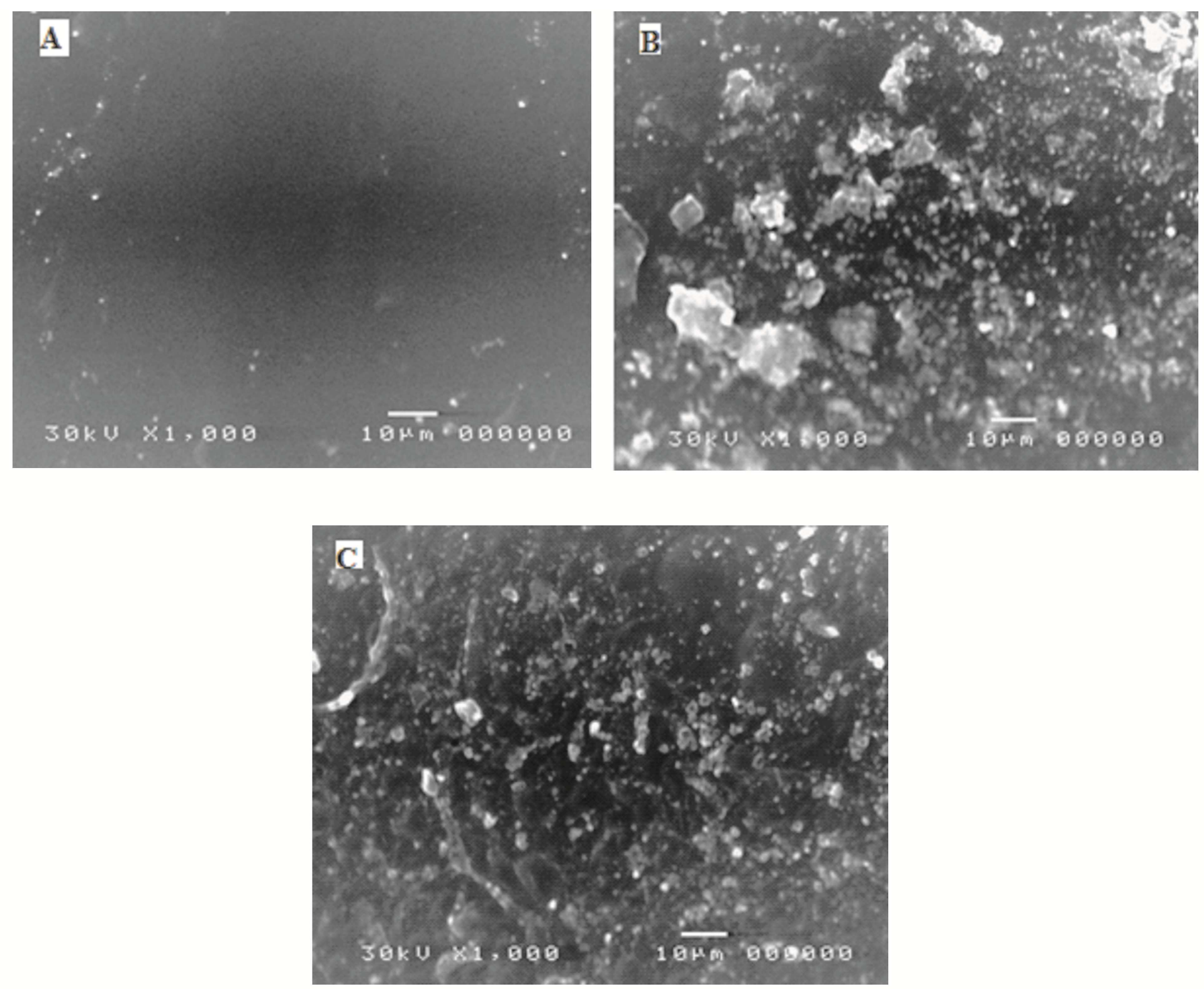

Figure 5

SEM of CMC films:(a) CMC-20\% Glycerol, (b) CMC/1.5\%TiO2 and (c) CMC/1.5\%TiO2 - 10kGy. 

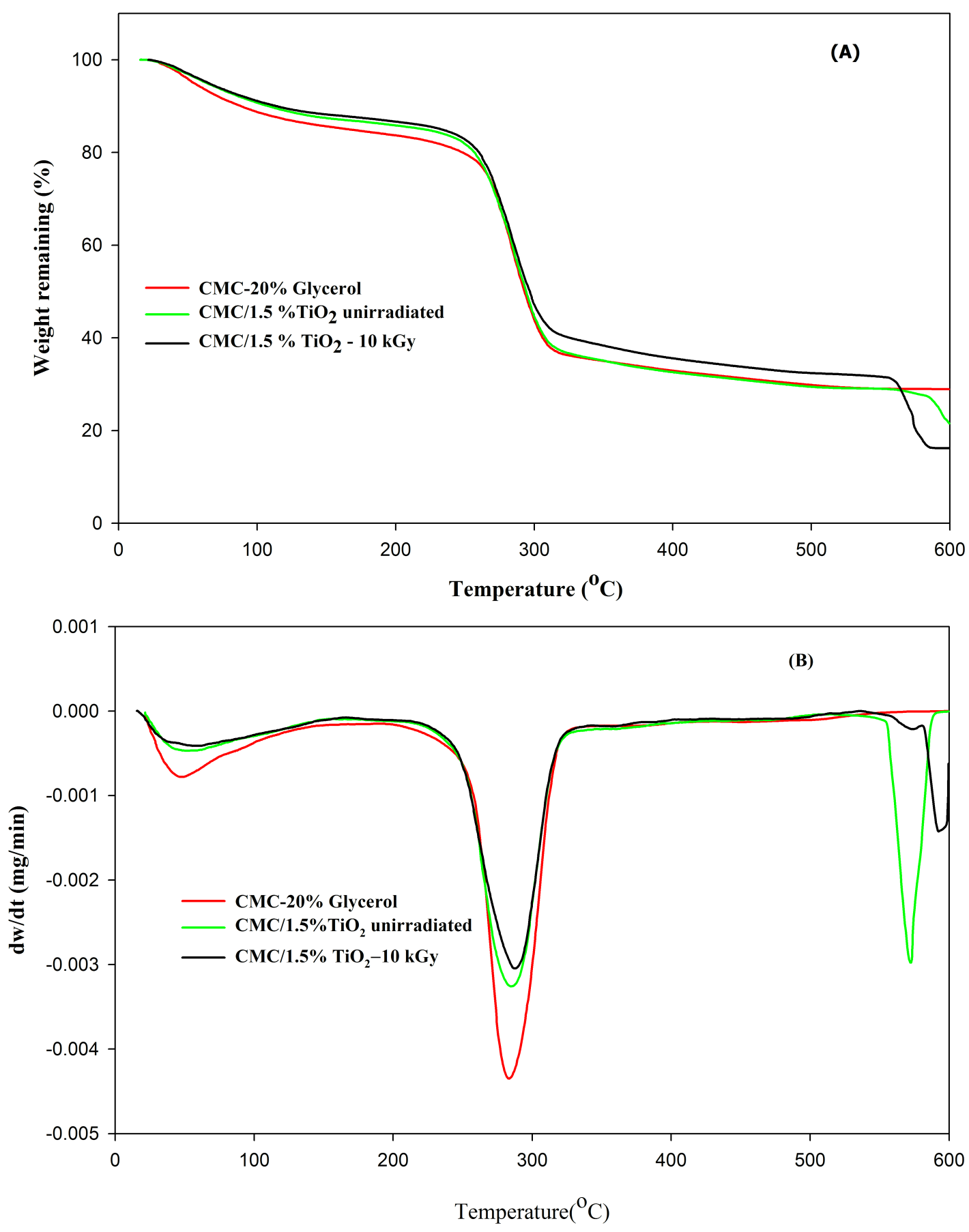

Figure 6

(A)TGA and (B) DTG thermograms of CMC-20\%Glycerol, CMC/1.5\%TiO2 and CMC-1.5\% TiO2 at 10kGy. 

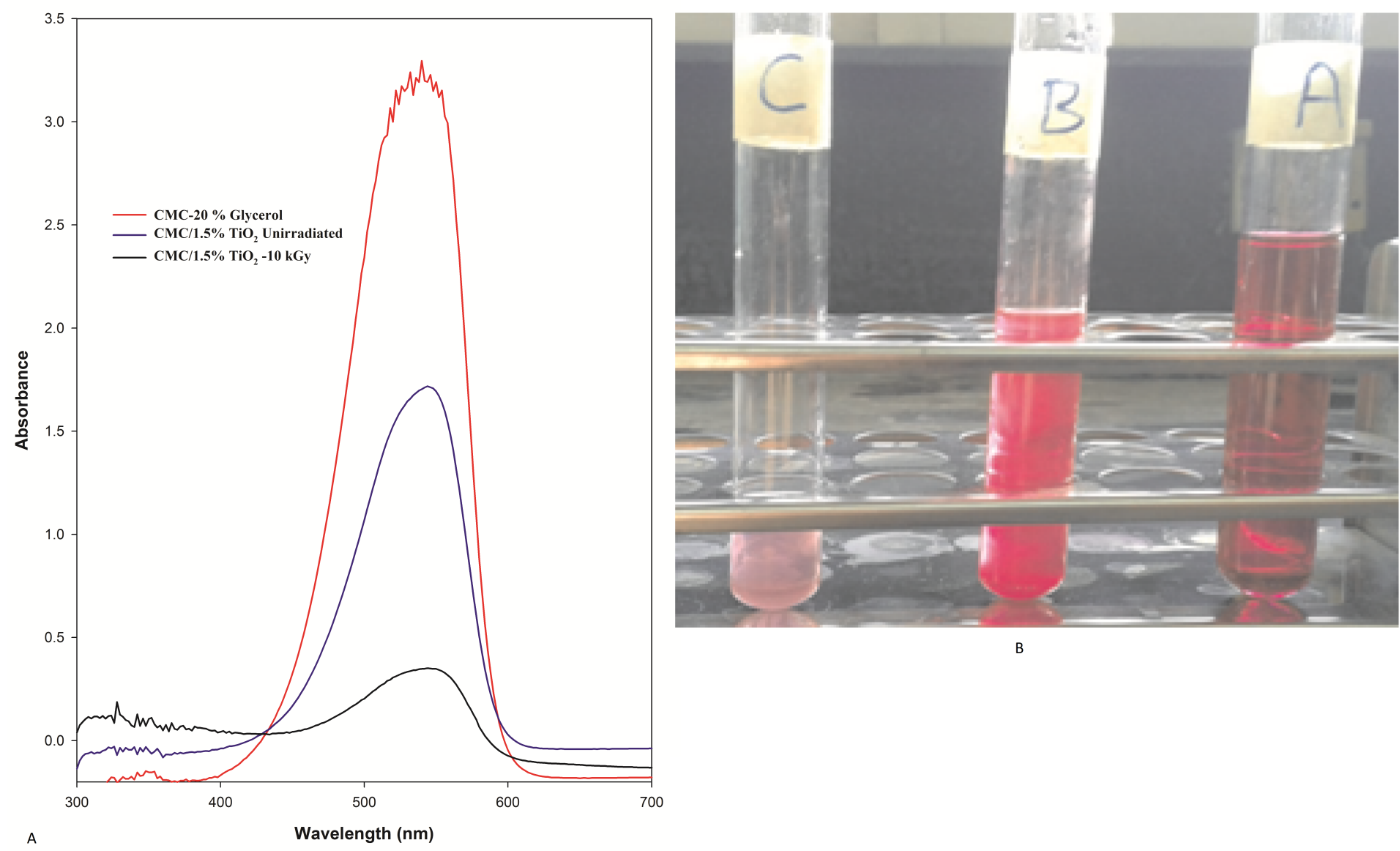

B

\section{Figure 7}

A. shows the change in the absorbance of the basic violet 7 dye solutions onto blank $\mathrm{CMC}$, irradiated and unirradiated $\mathrm{CMC} / \mathrm{TiO} 2$ composite after 24h. B. Effect of adsorbent type[ (A) pure CMC, (B) Unirradiated $\mathrm{CMC} / \mathrm{TiO} 2$ and (C) CMC/1.5\% TiO2-10 kGy] on the removal of the basic violet dye after $24 \mathrm{~h}$. 


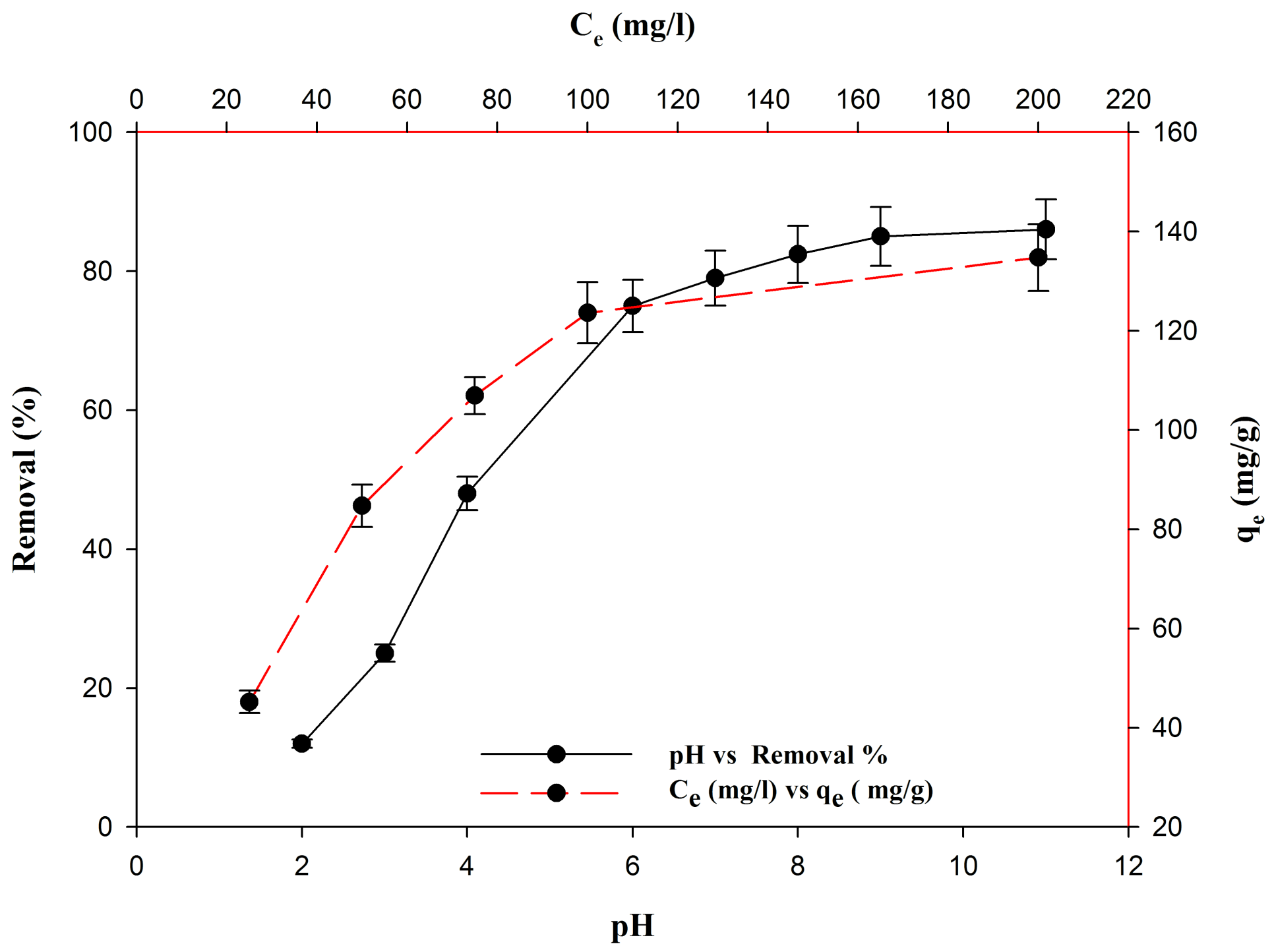

Figure 8

Effect of $\mathrm{pH}$ and initial concentration $(\mathrm{mg} / \mathrm{l})$ on the removal $(\%)$ and amount adsorbed $(\mathrm{mg} / \mathrm{g})$ of basic Violet 7 dye onto $\mathrm{CMC} / 1.5 \mathrm{TiO} 2-10 \mathrm{kGy}$ at conditions; adsorbent dosage $=0.2 \mathrm{~g}$ and contact time $=420$ min at room temperature $=298$ oK. 

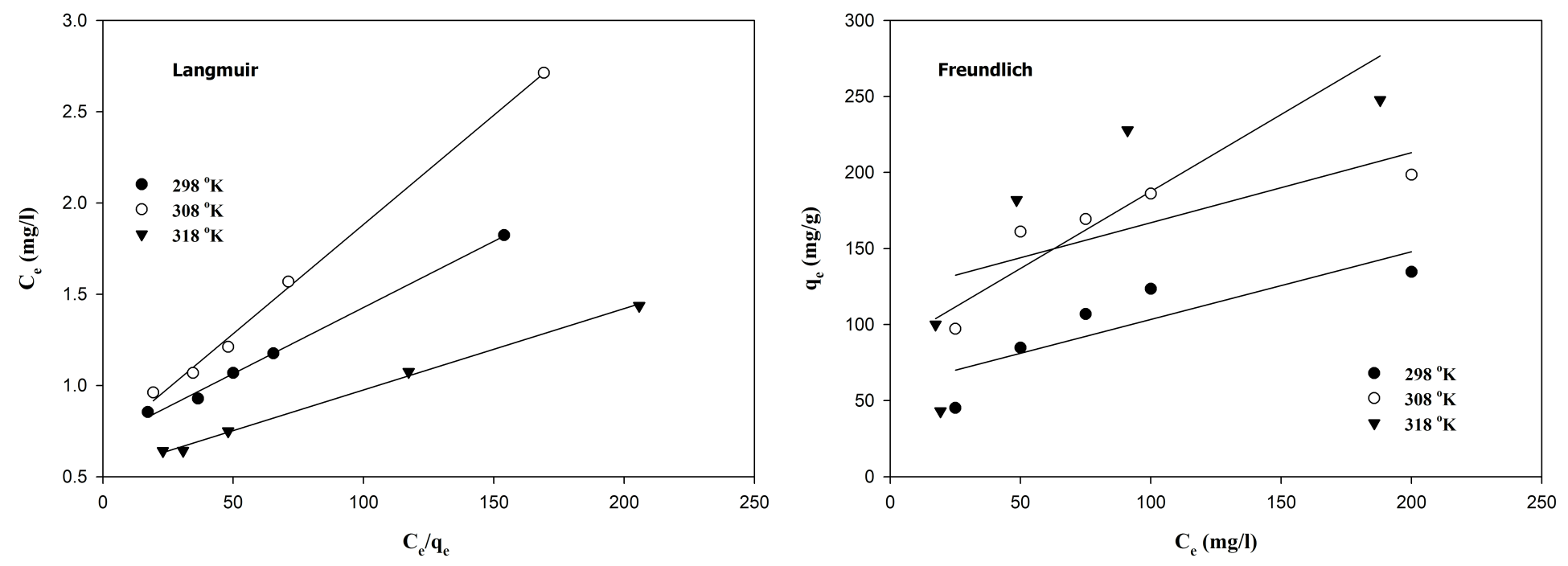

Figure 9

Effect of contact time (min.) and temperature (oK) on the amount adsorbed (qt)(mg/g) of Basic Violet 7 dye onto $\mathrm{CMC} / 1.5 \%$ TiO2- $10 \mathrm{kGy}$ composite film at the conditions; initial concentration $=100 \mathrm{mg} / \mathrm{l}$, adsorbent dose $=0.02 \mathrm{~g}$, solution volume $50 \mathrm{ml}$ and $\mathrm{pH}=8$.
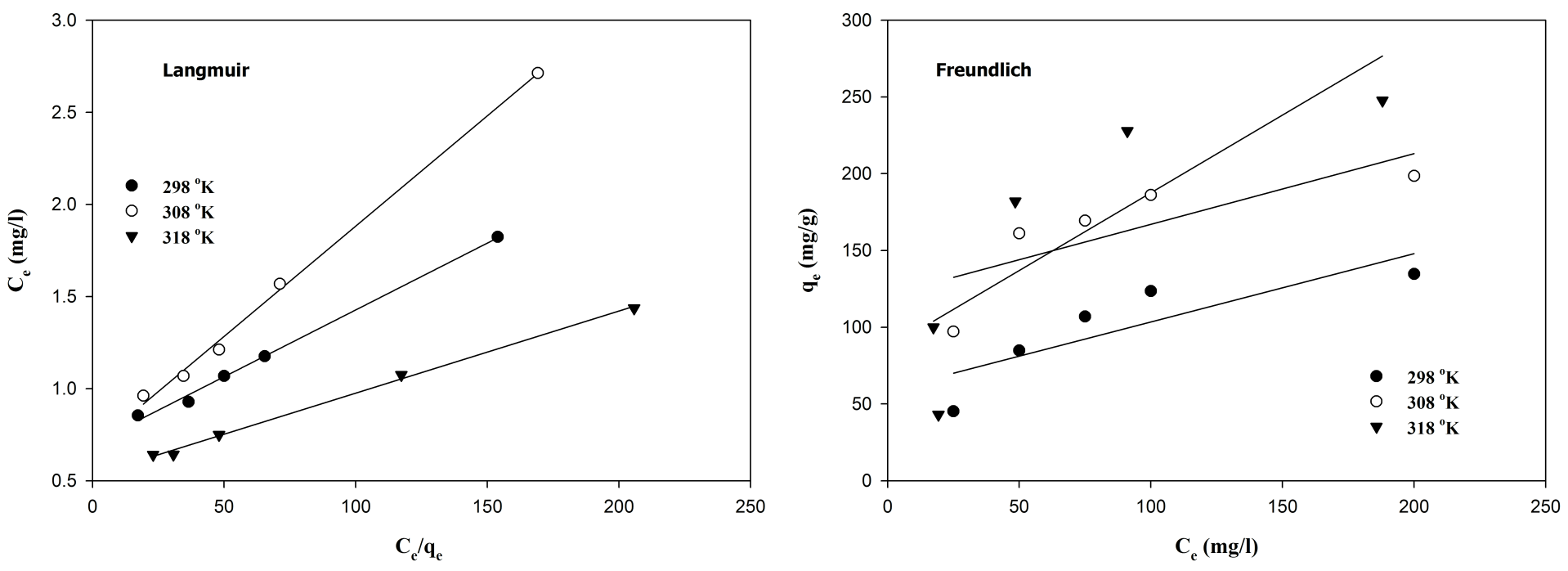

Figure 10

amount adsorbed of basic violet 7 dye fitted with the Langmuir model and Freundlich models. 

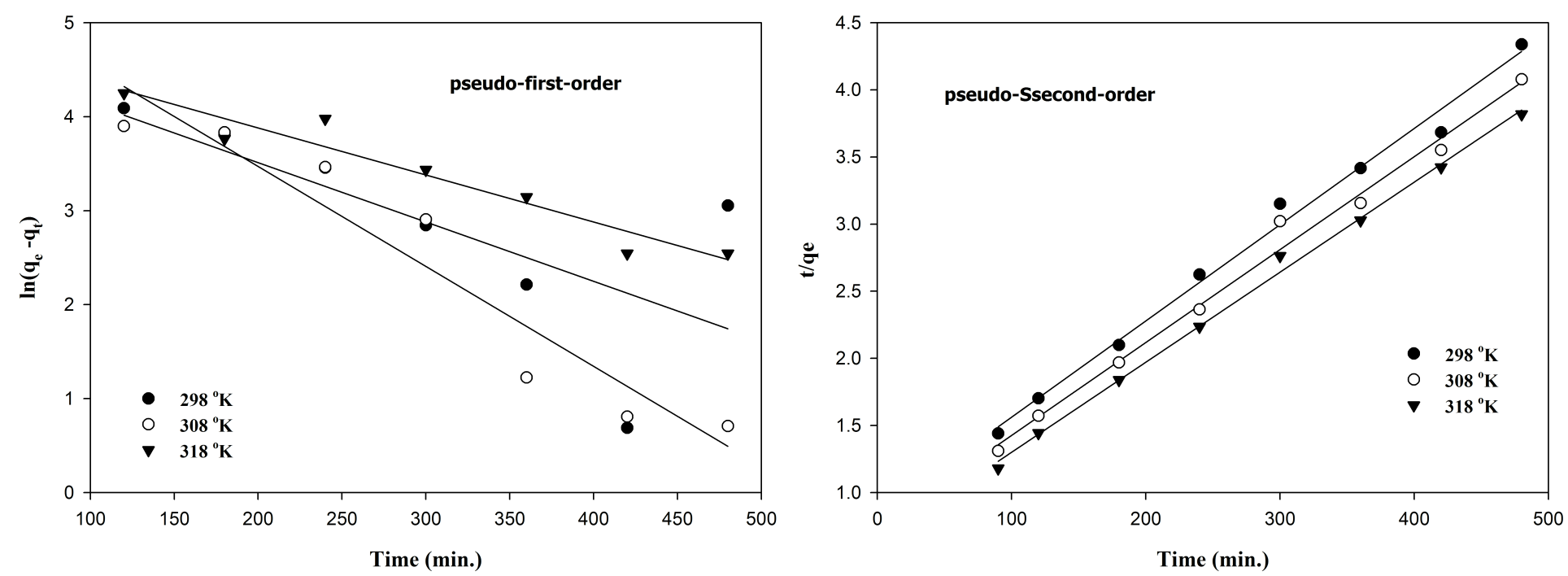

\section{Figure 11}

Fitted plots of the pseudo-first-order and pseudo-second-order kinetics of adsorption for basic violet dye onto $\mathrm{CMC} / 1.5 \%$ TiO2- $10 \mathrm{kGy}$.

\section{Supplementary Files}

This is a list of supplementary files associated with this preprint. Click to download.

- SupplementaryMaterial.docx 